\title{
Summary of: Sugars consumption in a low-income sample of British young people and adults
}

\section{FULL PAPER DETAILS}

1Department of Epidemiology and Public Health

University College London, London

${ }^{*}$ Correspondence to: Antiopi Ntouva

Email:a.ntouva@ucl.ac.uk

Refereed Paper

Accepted 13 March 2013

DOI: 10.1038/sj.bdj.2013.655

${ }^{\circledR}$ British Dental Journal 2013; 214: E2

\author{
A. Ntouva, ${ }^{* 1}$ G. Tsakos ${ }^{1}$ and R. G. Watt ${ }^{1}$
}

Objective To report the consumption of non-milk extrinsic sugars (NMES) among a low-income UK sample, compare it with nationally representative estimates and examine the association between socioeconomic position and NMES consumption among low income adults. Design Secondary analysis of the Low Income Diet and Nutrition Survey (LIDNS) data. Setting and subjects Two thousand, seven hundred and ninety-six adults and 415 young people from 2,477 households. Main outcome measures Mean NMES intakes (grams) and their percentage contribution to food energy, from dietary data collected via a 24-hour recall 'multiple pass' method. Results The low income sample consumed more NMES than the general population sample. The percentage of food energy from NMES exceeded the $11 \%$ target, especially among adolescents (17.2\% in males, $16.3 \%$ in females). After adjusting for age, men who finished full-time education aged 16 years consumed significantly more sugar $(p=0.028)$, whereas those who finished aged 18 consumed significantly less sugar ( $p=0.023$ ) than the reference group (finished aged 15$)$. No significant associations were found between NMES and socioeconomic variables in women. Conclusion Compared to the general population, the nutritional disadvantage of the most deprived segments of society relates primarily to excessive NMES consumption. In men, higher educational level appears to play a protective role against high sugar intakes.

\section{EDITOR'S SUMMARY}

Sugar ... once a commodity only attainable to the rich is now a treat (or a scourge) available to people from all socioeconomic groups. The vast majority of us have evolved to like sugar probably because sweetness intensity indicates energy density in food, while, for example, bitterness tends to indicate toxicity. This BDJ study confirms, however, that high sugar intake is a particular problem for low income adults in the UK.

Higher-quality diets are now associated with greater affluence and energy-dense, nutrient-poor diets are preferentially consumed by persons of lower socioeconomic status and of more limited economic means. Why is this such bad news?

A wealth of scientific evidence has shown that non-milk extrinsic sugars (NMES), those generally found in processed foods and drinks, are the most important factor in the development of dental caries. Not only that, but NMES are also linked to the development of other chronic conditions, such as obesity and cardio-metabolic diseases.

As well as demonstrating that NMES consumption is significantly higher among low-income adults, this $B D J$ study also touches on the reasons why more NMES are consumed by low income adults. It postulates that foods with a high level of sugars are often cheaper than nutrient-dense foods, thereby appealing to those with little disposable income. The study also points out that low income groups generally suffer from a lack of nutritional knowledge which could lead to unhealthier diet choices.

As it is so destructive I wonder if excess sugar consumption will ever become completely taboo in our society? We have a long way to go. How interesting that, even in dentistry with all its awareness of the importance of healthy eating, exhibition stands at dental conferences are still full of sweets and cakes to tempt delegates. Perhaps healthy-eat- ing promotions such as the BDA's current 'Make a meal of it' campaign (www.bda. org/makeamealofit) will turn the tide of public awareness and opinion in relation to sugar consumption. This study certainly shows that campaigns and policies that target the high sugar intake of low-income adults and children are a must for the UK.

The full paper can be accessed from the $B D J$ website (www.bdj.co.uk), under 'Research' in the table of contents for Volume 215 issue 1.

Ruth Doherty Managing Editor

DOI: 10.1038/sj.bdj.2013.656 
TO ACCESS THE BDJ WEBSITE TO READ THE FULL PAPER:

- BDA Members should go to www.bda.org.

- Click the 'login' button on the right-hand side and enter your BDA login details.

- Once you have logged in click the 'BDJ' tab to transfer to the BDJ website with full access.

IF YOUR LOGIN DETAILS DO NOT WORK:

- Get a password reminder: go to www.bda.org, click the login button on the right-hand side and then click the forgotten password link.

- Use a recommended browser: we recommend Microsoft Internet Explorer or Mozilla Firefox.

- Ensure that the security settings on your browser are set to recommended levels.

IF YOU HAVE NOT YET SIGNED UP TO USE THE BDA WEBSITE:

- Go to www.bda.org/getstarted for information on how to start using the BDA website.
IN BRIEF

- Provides an overview of macronutrient intakes in two UK populations.

- Improves understanding of the differences in sugars consumption between a deprived and a general population sample.

- Offers insight into how different socioeconomic factors affect sugar consumption in a low income population.

\section{COMMENTARY}

People on low incomes have poorer dental health than their wealthier counterparts, including higher rates of dental caries. Quantity and frequency of consumption of non-milk extrinsic sugars (NMES) are important modifiable risk factors in the aetiology of caries. The intake of NMES by low income groups is therefore of interest. This paper by Ntouva et al. provides information on intakes of NMES from the UK low income diet and nutrition survey (LIDNS) $^{1}$ and compares their intakes with those from the UK rolling national diet and nutrition survey (NDNS, years one and two). ${ }^{2}$ They found that although energy and macronutrient intakes were similar for young people (11-18 years), adults (1964 years) and older adults (65+ years), the quantity and percentage contribution to energy of NMES was higher in the LIDNS sample compared to the NDNS for all age groups. The actual, rather than reported, intake of NMES is likely to be higher in both samples. The mean reported energy intakes for all groups in both samples were low when compared with estimated average requirements, ${ }^{3}$ suggesting that many participants under-reported their dietary intake.

The authors also found a significant difference within men in intake of NMES by age of leaving education. Men who left full-time education at the age of 16 years consumed $8 \mathrm{~g} / \mathrm{d}$ more NMES than men leaving at age 15 years, whereas men leaving at 18 years consumed $11 \mathrm{~g} / \mathrm{d}$ more. To put this into context, a heaped teaspoon of sugar weighs $6 \mathrm{~g},{ }^{4}$ so although significant these differences are small. The authors' conclu- sion that "the nutritional disadvantage of the most deprived segments of society relates primarily to excessive NMES consumption' is not warranted, however, as they did not consider other nutrients. In the report of LIDNS, ${ }^{1}$ intakes of foods and nutrients are compared to earlier NDNS surveys of children, adults and older adults. The most recently published of these is the NDNS adults aged 19-64 years. ${ }^{5}$ As in this paper, intakes of NMES were higher in the LIDNS participants. However, intakes of all minerals and all vitamins except vitamin A were lower, as were intakes of dietary fibre and fruit and vegetables. Clearly, the nutritional disadvantage experienced by the most deprived is greater than simply intake of NMES. Interventions to reduce the quantity and frequency of NMES intake have the potential to address these other nutritional deficiencies.

\section{Jane Bradbury}

Senior Lecturer in Nutrition

University of Huddersfield

1. Nelson M, Erens R, Bates B, Church C, Boshier T. Low income diet and nutrition survey. Volume 2: food consumption. Nutrient intake. London: TSO, 2007. Online article available at $h \mathrm{ttp}: / /$ tna.europarchive. org/20110116113217/http://www.food.gov.uk/ multimedia/pdfs/lidnsvol02 (accessed April 2013).

2. Bates B, Lennox A, Bates C, Swan G. National diet and nutrition survey: headline results from years 1 and 2 (combined) of the rolling programme (2008-9 - 2009-10). London: DH, 2011.

3. Scientific Advisory Committee on Nutrition. Dietary reference values for energy. London: TSO, 2011. Online article available at http://www. sacn.gov.uk/pdfs/sacn_dietary_reference_values for energy.pdf (accessed April 2011).

4. Food Standards Agency. Food portion sizes, 3rd ed. London: TSO, 2002

5. Henderson L, Irving K, Gregory J et al. The national diet and nutrition survey: adults aged 19 to 64 years. Vitamin and mineral intake and urinary analytes. London: TSO, 2003. Online article available at http://www.food.gov.uk/multimedia/pdfs/ndnsv3.pdf (accessed April 2013).

\section{AUTHOR QUESTIONS AND ANSWERS}

1. Why did you undertake this research? Non-milk extrinsic sugars consumption (NMES) has been consistently identified as the most important factor in the development of dental caries. Although diet and nutrition are important factors contributing to health inequalities, limited detailed information has been available on NMES consumption amongst low-income population groups, where health-compromising dietary patterns would be expected to be more widespread. We wanted to investigate NMES consumption in a materially deprived UK sample, and explore if and how the sample's socioeconomic characteristics affects their intakes. We also wanted to compare these with a nationally representative general population sample.

2. What would you like to do next in this area to follow on from this work?

A multitude of information has been collected from the Low Income National Diet and Nutrition Survey (LIDNS) including - among others - anthropometric, nutritional and haematological data. It would therefore be interesting to explore further any relationships between NMES intakes and these variables in the sample. We are particularly interested in investigating further the association if any, between NMES consumption and a number of risk factors for cardio-metabolic diseases in this study population. We would like to assess if NMES intake is an independent factor of metabolic disease outcomes (using measures such as waist circumference, cholesterol, triglycerides and blood pressure). 